Article

\title{
Controlling and Predicting the Dissolution Kinetics of Thermally Oxidised Mesoporous Silicon Particles: Towards Improved Drug Delivery
}

\author{
Feng Wang ${ }^{1,+}$, Timothy J. Barnes ${ }^{1}$ and Clive A. Prestidge ${ }^{1,2, *}$ \\ 1 School of Pharmacy and Medical Sciences, University of South Australia, Adelaide, SA 5000, Australia; \\ frank.wang@monash.edu (F.W.); tim.barnes@unisa.edu.au (T.J.B.) \\ 2 ARC Centre of Excellence in Convergent Bio-Nano Science and Technology, University of South Australia, \\ Adelaide, SA 5000, Australia \\ * Correspondence: clive.prestidge@unisa.edu.au; Tel.: +61-883-022-438 \\ + Departed.
}

Received: 25 October 2019; Accepted: 25 November 2019; Published: 28 November 2019

check for updates

\begin{abstract}
Porous silicon (pSi) continues to receive considerable interest for use in applications ranging from sensors, biological scaffolds, therapeutic delivery systems to theranostics. Critical to all of these applications is $\mathrm{pSi}$ degradation and stabilization in biological media. Here we report on progress towards the development of a mechanistic understanding for the dissolution behavior of native (unoxidized) and thermally oxidized $\left(200-600{ }^{\circ} \mathrm{C}\right) \mathrm{pSi}$ microparticles. Fourier transform infrared (FTIR) spectroscopy was used to characterize the pSi surface chemistry after thermal oxidation. PSi dissolution was assessed using a USP method II apparatus by monitoring the production of orthosilicic acid, and the influence of gastro-intestinal (GI) fluids were examined. Fitting pSi dissolution kinetics with a sum of the exponential model demonstrated that the dissolution process strongly correlates with the three surface hydride species and their relative reactivity, and was supported by the observed FTIR spectral changes of pSi during dissolution. Finally, the presence of GI proteins was shown to hamper $\mathrm{pSi}$ dissolution by adsorption to the $\mathrm{pSi}$ surface acting as a barrier preventing water attack. These findings are significant in the optimal design of pSi particles for oral delivery and other controlled drug delivery applications.
\end{abstract}

Keywords: porous silicon; drug delivery system; dissolution; oxidation; Fourier transform infrared (FTIR); kinetics

\section{Introduction}

More than 20 years after the initial discovery of porous silicon (pSi) photoluminescence by Professor Canham, and his subsequent work on the fabrication of bioactive pSi [1], there remains significant ongoing interest in its biomedical applications, including therapeutic delivery, medical imaging, and theranostics [2-13]. PSi possesses a highly tuneable porous nanostructured network and can be fabricated into a variety of different forms, ranging from thin films [14], nanowires [15], and micro- and nanoparticles [6,16-18]. PSi is typically produced via an electrochemical etching process (e.g., see [19]); however, there are ongoing efforts to more efficiently produce pSi nanoparticles (e.g., [20]). The surface chemistry of pSi also offers opportunities for extensive modification, e.g., thermal oxidation [21-23], amination [24], and chemical modification [19,25,26].

Many biomedical applications of pSi are influenced and dependent on the balance between dissolution/erosion versus oxidation of the silicon matrix that occurs in aqueous bio-relevant environments. The $\mathrm{Si}-\mathrm{Si}$ and $\mathrm{Si}-\mathrm{H}$ bonds are intrinsically weaker than their oxidized analogues, $\mathrm{Si}-\mathrm{O}-\mathrm{Si}$ 
and $\mathrm{Si}-\mathrm{OH}$ [27]. When native pSi is submerged in water, the initial reaction occurring is the oxidation of the $\mathrm{Si}-\mathrm{H}$ surface species by solvated $\mathrm{OH}$, which subsequently acts as a nucleation substitute for removal of the oxidized surface hydrides to form orthosilic acid, as described in Equations (1) and (2). Once the surface $\mathrm{Si}-\mathrm{H}$ has been removed a new layer of surface $\mathrm{Si}-\mathrm{H}$ is formed, and the pSi erosion cycle continues [28-30].

$$
\begin{gathered}
\equiv \mathrm{Si}-\mathrm{SiH}(\mathrm{s})+\mathrm{HOH} \rightarrow \equiv \mathrm{Si}-\mathrm{SiOH}(\mathrm{s})+\mathrm{H}_{2}(\mathrm{~g}) \\
\equiv \mathrm{Si}-\mathrm{SiOH}(\mathrm{s})+\mathrm{HOH} \rightarrow \equiv \mathrm{Si}-\mathrm{H}(\mathrm{s})+\mathrm{Si}(\mathrm{OH})_{4}(\mathrm{aq})
\end{gathered}
$$

Previous pSi dissolution studies have typically involved direct visualization/monitoring of a planar pSi wafer surface using techniques such as atomic force microscope (AFM), scanning electron microscope (SEM) [1,31,32], photoluminescent and infrared spectroscopies [33,34]. However, these approaches provide only qualitative or semi-quantitative topographic and/or pSi speciation information to assess pSi degradation. Alternatively, orthosilicic acid, the soluble product of pSi degradation, can be quantitatively measured using either a molybdenum blue assay [35] or inductively coupled plasma atomic emission spectroscopy (ICP-AES), and hence accurate mass loss kinetics of pSi during dissolution can be obtained. Using this approach, Anderson et al. investigated the dissolution of pSi films with varied porosity (60-80\%) and over a $\mathrm{pH}$ range 2 to 8; however, they did not elucidate specific dissolution mechanisms in their analysis [36]. A number of studies have demonstrated correlations between drug release kinetics and pSi degradation as well as the influence of the local tissue environment [3,37-39].

We have previously reported on the use of thermally oxidized pSi microparticles for oral delivery of poorly water-soluble non-steroidal anti-inflammatory drugs [5,40]. In this study, we quantitatively investigate the dissolution kinetics of both native (unoxidised) and thermally oxidized (200 to $\left.600{ }^{\circ} \mathrm{C}\right)$ pSi microparticles in buffer solutions and simulated gastro-intestinal (GI) fluids, and use Fourier transform infrared (FTIR) spectroscopy to determine surface chemical changes. The pSi dissolution kinetics was fitted with a sum of exponentials mathematical model, which reflects the pSi surface speciation. These findings give improved insight into pSi particle dissolution with specific reference to its use in oral delivery.

\section{Materials and Methods}

\subsection{Materials}

PSi powder and wafer samples (p-type silicon) used in this investigation were supplied by pSiMedica Ltd. (Malvern, UK) and showed a porosity of $\sim 70 \%$, a specific surface area (SSA) of $310.2 \mathrm{~m}^{2} / \mathrm{g}$, and an average particle size of $49.4 \mu \mathrm{m}$ (note: $\mathrm{D}_{10} 23.2, \mathrm{D}_{90} 130.4 \mu \mathrm{m}$ ) as determined by a laser diffraction (Malvern Mastersizer 2000 software, version 4.0, Malvern Mastersizer 2000, Malvern Co, Malvern, UK). PSi thermal oxidation was performed in a clean oven by heating in air at $40 \mathrm{~K} \mathrm{~min}^{-1}$ to a specific oxidation temperature in the range $473-873 \mathrm{~K}$ for $1 \mathrm{~h}$, before convective cooling to ambient temperature.

Tween 80 (Polysorbate 80) and sodium dodecyl sulfate (SDS) were purchased from Chem-Supply Pty Ltd., Adelaide, Australia. Trizma ${ }^{\circledR}$ buffer solution pH 7.2 (1 M, tris(hydroxymethyl)aminomethane $\mathrm{HCl}$ ), pancreatin from porcine pancreas (activity equivalent to $8 \times$ USP specification) and pepsin (lyophilized powder from porcine gastric mucosa, 800-2,500 units/mg protein), were purchased from Sigma-Aldrich Australia Pty Ltd, Sydney, Australia. All the other chemicals were analytical grade used as received. High purity water (Milli- $Q^{\circledR},<18 \mathrm{~m} \Omega \mathrm{cm}^{-1}$ ) was used throughout the experiments.

\subsection{In Vitro pSi Dissolution}

pSi dissolution was conducted with a VanKel ${ }^{\mathrm{TM}}$ (VK 6010) dissolution test station attached with apparatus USP II (paddles, Edison, NJ, USA) at $37.0{ }^{\circ} \mathrm{C}( \pm 0.5)$. PSi particles $(\sim 50 \mathrm{mg}$, accurately 
weighed) were pre-wetted with $200 \mu \mathrm{L}$ of ethanol and then transferred into $500 \mathrm{~mL}$ of $0.05 \mathrm{M}$ Tris buffer solution at pH 7.2 (or alternative dissolution medium as indicated). At predetermined time points, aliquots of media $(5 \mathrm{~mL})$ were collected and filtered with a Millex ${ }^{\circledR}$ syringe filter $(0.22 \mu \mathrm{m}$ PTFE membrane, Merck, Darmstadt, Germany). The aliquots were analyzed to determine the concentration of silicic acid using a validated molybdenum blue spectroscopic assay (Varian Cary@50 UV-Vis Spectrophotometer, Walnut Creek, CA, USA). For dissolution experiments performed in phosphate buffer solution ( $\mathrm{pH}$ 6.8), the samples were analyzed using ICP-AES (Horiba Jobin-Yvon ACTIVA ICP-AES spectrometer, Longjumeau, France), since phosphate interferes with the molybdenum blue assay. All the experiments were conducted in duplicate unless otherwise indicated.

\subsection{Fourier Transform Infrared (FTIR) Spectroscopy}

Infrared transmission spectra of pSi particle samples were obtained with a Nicolet Magna-IR $750^{\mathrm{TM}}$ FTIR spectrometer equipped with a liquid nitrogen-cooled mercury-cadmium-telluride (MCT) detector (Madison, WI, USA). The particles were pressed into KBr discs and 256 scan spectra were recorded with a $4 \mathrm{~cm}^{-1}$ resolution. Additionally, solid residues from the dissolution study were extracted, thoroughly rinsed with Milli-Q water and then dried at $105^{\circ} \mathrm{C}$ for $2 \mathrm{~h}$ in an oven prior to FTIR analysis.

\subsection{Contact Angle Measurements}

Water contact angle measurements were performed on pSi wafers using a static sessile drop method (Optical Contact Angle system, OCA15EC, SCA 20 version 2 software). The wafers were either unoxidized or thermally oxidized using equivalent conditions to those used for the $\mathrm{pSi}$ microparticles.

\section{Results}

\subsection{Preparation and Characterisation of Thermally Oxidised pSi Microparticles}

Thermal oxidation of pSi particles was carried out at 200, 300, 400, 500, and $600{ }^{\circ} \mathrm{C}$ for $1 \mathrm{~h}$ in a clean furnace, open to the atmosphere. The surface area and porous nature of the thermally oxidized pSi samples are presented in Table 1.

Table 1. Surface area and pores volume/size of pSi samples.

\begin{tabular}{ccccc}
\hline $\begin{array}{c}\text { Oxidation } \\
\text { Temperature }\left({ }^{\circ} \mathbf{C}\right)\end{array}$ & Label & BET-SSA $\left(\mathbf{m}^{\mathbf{2}} \mathbf{g}\right)$ & $\begin{array}{c}\text { Mesopore Volume } \\
(\mathbf{m L} / \mathbf{g})\end{array}$ & $\begin{array}{c}\text { Mesopore } \\
\text { Diameter }(\mathbf{n m})\end{array}$ \\
\hline unoxidized pSi & $\mathrm{pSi}$ & 325.7 & 0.77 & 10.1 \\
200 & OXpSi-200 & 312.5 & 0.74 & 10.1 \\
300 & OXpSi-300 & - & - & - \\
400 & OXpSi-400 & 247.7 & 0.61 & 9.6 \\
500 & OXpSi-500 & - & - & - \\
600 & OXpSi-600 & 243.8 & 0.48 & 9.3 \\
\hline
\end{tabular}

Upon thermal oxidation of the pSi particles, there is a reduction in the surface area and mesopore volume; this is due to the increased molecular volume of silicon oxidation products, causing constriction of the mesoporous pathways within the $\mathrm{pSi}$. The changing $\mathrm{Si}$ speciation upon thermal oxidation was monitored using FTIR spectroscopy, with the IR spectra for both the native and thermally oxidized pSi shown in Figure 1. For the native, unoxidized pSi, a composite band with triplet peaks at 2140, 2105, and $2075 \mathrm{~cm}^{-1}$ was observed. These absorption bands were assigned to Si-Hx stretching modes $(x=3$, 1, 2; from high frequency to low) [41,42], the higher intensity of the peak at $2075 \mathrm{~cm}^{-1}$ indicated that dihydride $\left(\mathrm{SiH}_{2}\right)$ was the more predominant surface species, in agreement with previous reports [43,44]. Upon thermal oxidation of the pSi at $200^{\circ} \mathrm{C}$, this band was observed to shift to a higher frequency, which according to previous literature is attributed to pore propagation occurring only in the (100) direction $[45,46]$. 


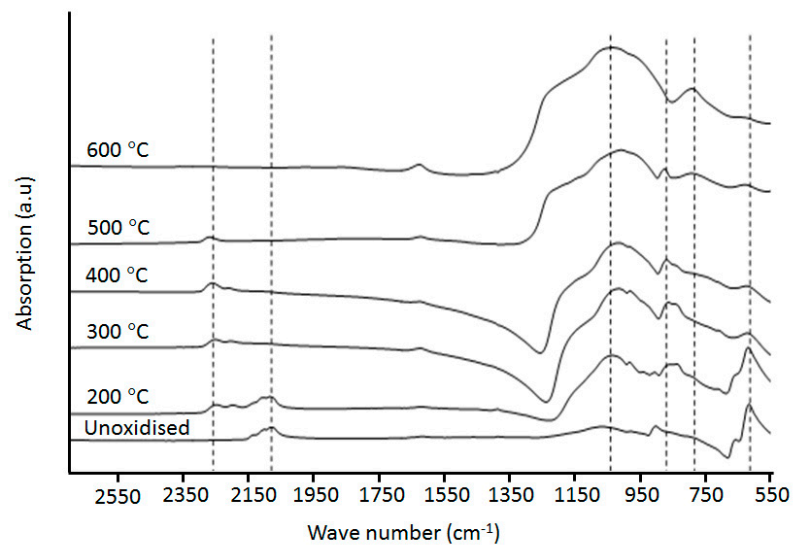

Figure 1. Infrared spectra of pSi particles treated at different temperatures.

In the finger print region $\left(<1000 \mathrm{~cm}^{-1}\right)$, a sharp absorption band at $615 \mathrm{~cm}^{-1}$ with a shoulder at $660 \mathrm{~cm}^{-1}$ was observed for native and $200^{\circ} \mathrm{C}$ oxidized pSi samples, attributed to Si-Si crystal mode and $\mathrm{Si}-\mathrm{H}_{2}$ wagging modes, respectively $[27,47]$, indicating that only the surface hydride species underwent oxidation, rather than the bulk Si. A new band at $860 \mathrm{~cm}^{-1}$ was observed with increasing oxidation temperature of the $\mathrm{pSi}$, which was assigned as an oxidised $\mathrm{O}-\mathrm{SiHx}$ deformation mode [48]. The sharp band at $905 \mathrm{~cm}^{-1}$ was attributed to a Si- $\mathrm{H}_{2}$ scissoring mode, while the broad band at $1030 \mathrm{~cm}^{-1}$ was attributed to $\mathrm{Si}-\mathrm{O}-\mathrm{Si}$ asymmetric bending. The increased intensity of the $1030 \mathrm{~cm}^{-1}$ band and the decreased intensity of absorption $\left(\mathrm{Si}-\mathrm{H}_{2}\right.$ scissoring) implies that mild oxidation had occurred. This feature became more pronounced with increasing oxidation temperature $\left(>300^{\circ} \mathrm{C}\right)$. The presence of this band $\left(1030 \mathrm{~cm}^{-1}\right)$ in samples not exposed to high temperatures indicates that oxidation of the pSi sample was slowly occurring under ambient conditions. Finally, a band was observed at $2250 \mathrm{~cm}^{-1}$, associated with the backbond oxidized $\mathrm{Si}-\mathrm{Hx}$, i.e., (Si-O-)Si-Hx [42].

The spectra of the thermally oxidized pSi particles at $300^{\circ} \mathrm{C}$ and above displayed more extensive evidence of oxidation characteristics. The bands at 660,905 , and $2075-2140 \mathrm{~cm}^{-1}$ disappeared; these bands were associated with $\mathrm{Si}-\mathrm{H}_{2}$ wagging, scissoring, and $\mathrm{Si}-\mathrm{Hx}$ stretching modes. The band at 2250 and $2205 \mathrm{~cm}^{-1}$ due to the backbond oxidized Si-Hx stretching became more profound. These absorptions could be precisely assigned to $\mathrm{OxSiHx}$ groups with oxygen-saturated state, i.e., $\mathrm{O}_{3} \mathrm{SiH}$ $\left(2250 \mathrm{~cm}^{-1}\right), \mathrm{O}_{2} \mathrm{SiH}_{2}\left(2200 \mathrm{~cm}^{-1}\right), \mathrm{OSiH}_{3}\left(2160 \mathrm{~cm}^{-1}\right)$ according to the literature [27]. A broad band peaking at $1030 \mathrm{~cm}^{-1}$ became more intense with a growing protruded shoulder compared to that at $20{ }^{\circ} \mathrm{C}$, in agreement with previous observation [49]. The band at $612 \mathrm{~cm}^{-1}$ associated with bulk Si-Si decreased, indicating oxidation had started altering the $\mathrm{Si}-\mathrm{Si}$ "skeleton" at $300{ }^{\circ} \mathrm{C}$, something that has been referred to previously as a threshold temperature for silicon thermal oxidation [43,47]. The infrared spectrum obtained for OXpSi-400 was similar to that for OXpSi-300, except that the band at $2250 \mathrm{~cm}^{-1}$ had increased in intensity.

The pSi samples treated at $500-600{ }^{\circ} \mathrm{C}$ showed more significant oxidation features in their infrared spectra. For oxidation at $>500{ }^{\circ} \mathrm{C}$, a new absorption band appeared at $800-790 \mathrm{~cm}^{-1}$ due to the asymmetric and symmetric mode of $\mathrm{Si}-\mathrm{O}$, which is often observed with fully oxidized silicon; its intensity further increased with oxidation at 600 and $800{ }^{\circ} \mathrm{C}$ (data not shown). The single band at $2250 \mathrm{~cm}^{-1}$ instead of the duplet and triplet peaks from pSi sample oxidized at $300-400{ }^{\circ} \mathrm{C}$ indicated that there was only $\mathrm{SiH}$ with fully oxidized $\mathrm{Si}-\mathrm{Si}$ backbonds (i.e., $\mathrm{Si}-\mathrm{O}-\mathrm{Si}$ ) on pSi surfaces. The phenomenon of $\mathrm{Si}-\mathrm{Si}$ backbond oxidation can be explained by bond energy calculations, i.e., the bond strength of surface hydride $(\mathrm{Si}-\mathrm{H})$ increases with the increase of oxidation degree of its $\mathrm{Si}-\mathrm{Si}$ backbond. Thus, the survival of the surface $\mathrm{Si}-\mathrm{H}$ bond at $500{ }^{\circ} \mathrm{C}$ would be the one that has three oxidized backbonds, i.e., $\mathrm{H}-\mathrm{Si}(\mathrm{O})_{3}$ [27]. Eventually, surface $\mathrm{Si}-\mathrm{H}$ disappeared from pSi treated at $600{ }^{\circ} \mathrm{C}$ as dehydrogenation takes place, in agreement with a previous observation from annealing a silicon wafer at this temperature [50]. 
Furthermore, there is a strong correlation between pSi surface chemistry and the water contact angle, as shown in Figure 2 where both the integrated IR absorbance and contact angle are plotted against pSi oxidation temperature.

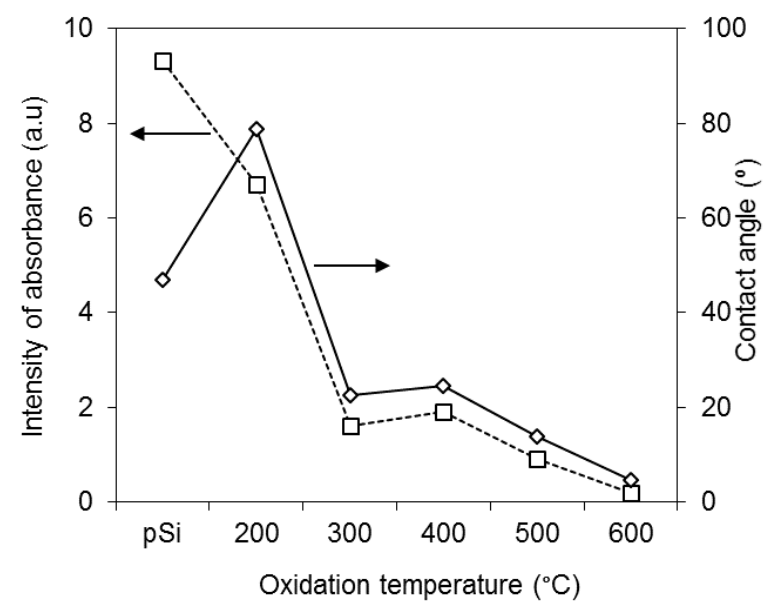

Figure 2. Correlation of the water contact angle measured using the Sessile drop technique $(\diamond)$ and the integrated absorbance from the $\mathrm{Si}-\mathrm{Si}$ bending and $\mathrm{Si}-\mathrm{H}_{2}$ wagging modes at $615-660 \mathrm{~cm}^{-1}(\square)$ for pSi samples oxidized at $200-600{ }^{\circ} \mathrm{C}$ in comparison with unoxidized pSi.

In summary, the thermal oxidation of pSi particles in this study follows the backbond oxidation phenomenon that has previously been observed with the oxidation of hydride passive silicon wafers $[27,47,51,52]$. The infrared spectra of $\mathrm{pSi}$ samples treated below $400{ }^{\circ} \mathrm{C}$ indicate that the $\mathrm{Si}-\mathrm{Si}$ backbonds of the surface hydrides were only partially oxidized. The Si-Si backbonds were fully oxidized at $500{ }^{\circ} \mathrm{C}$, while at $600{ }^{\circ} \mathrm{C}$, all the surface hydrides were diminished as dehydrogenation occurred, and the bulk Si-Si bonds were also oxidized, as shown schematically in Figure 3.

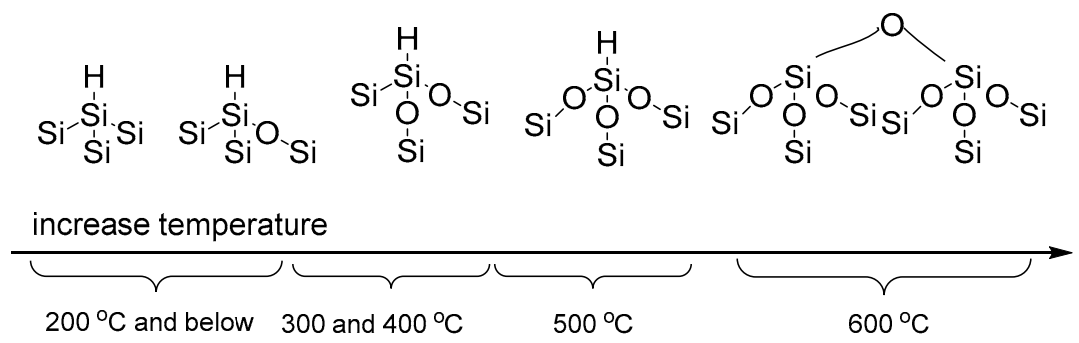

Figure 3. Schematic of pSi surface chemistry (only monohydride is depicted here) during thermal oxidation at elevated temperature.

\subsection{Dissolution of Unoxidized and Thermally Oxidised $p S i$}

Dissolution profiles in Tris buffer solution at $\mathrm{pH} 7.2$ for $\mathrm{pSi}$ particles of different levels of oxidation are presented in Figure 4. Unoxidized/native pSi particles rapidly dissolve (see Figure 4a), with approximately $52 \% w / w$ dissolved before the first sampling time point at $5 \mathrm{~min}$. In comparison, OXpSi- $200{ }^{\circ} \mathrm{C}$ dissolved $37 \%$ of its initial mass in the first $10 \mathrm{~min}$. The dissolution was accompanied by bubbling hydrogen gas due to the hydrolysis of hydrogen passivated surfaces [31,34]. The fast dissolution of the unoxidized pSi continued up to the first hour-time point when about $90 \%$ of the initial mass was lost while the remaining $10 \%$ pSi particles dissolved markedly slower over $7 \mathrm{~h}$; this was likely due to oxidation that took place concurrently along with dissolution, which resulted in the formation of $\mathrm{Si}-\mathrm{O}$ bonds which are less reactive than $\mathrm{Si}-\mathrm{Si}$ bonds. 


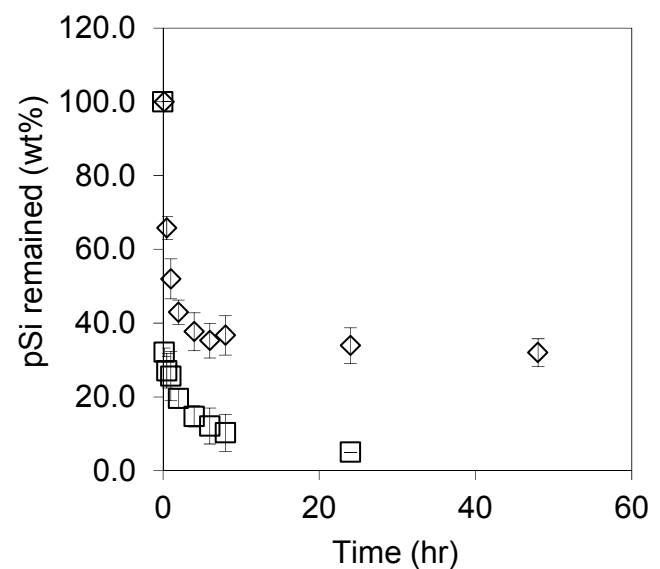

(a)

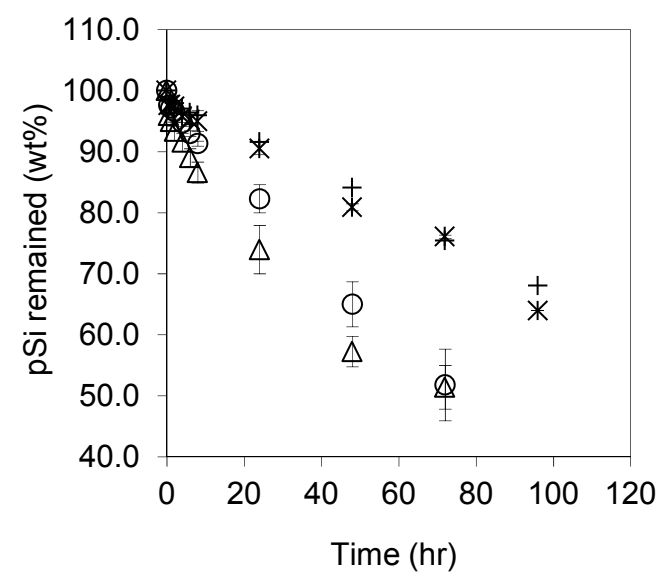

(b)

Figure 4. (a) Dissolution profiles of the unoxidized $\mathrm{pSi}(\square)$ and oxidized at $200^{\circ} \mathrm{CpSi}(\diamond)$, and (b) samples oxidized at $300(\triangle), 400(\bigcirc), 500(\times)$, and $600{ }^{\circ} \mathrm{C}(+)( \pm$ s.d., $n=2)$.

Dissolution profiles for $\mathrm{pSi}$ particles oxidized at temperatures $>300{ }^{\circ} \mathrm{C}$ are shown in Figure $4 \mathrm{~b}$ and are different from the unoxidized and OXpSi-200 samples. The more highly oxidized pSi samples dissolved with an almost linear reduction in pSi mass observed over time. The dissolution profiles of pSi particles oxidized at 300 and $400{ }^{\circ} \mathrm{C}$ were very similar, with approximately $65 \%$ mass reduction after $72 \mathrm{~h}$. In contrast, for pSi particles oxidized at higher oxidation temperatures $\left(500\right.$ and $\left.600{ }^{\circ} \mathrm{C}\right)$ a reduction in the dissolution rate was observed, i.e., $\sim 40 \% \mathrm{pSi}$ remaining after $96 \mathrm{~h}$. This is attributed to differences in the relative reactivity of the $\mathrm{pSi}$ species present. Indeed, the distinct difference between the dissolution behavior of the $\mathrm{pSi}$ oxidized at 200 versus $300^{\circ} \mathrm{C}$ suggests a transition in the relative fraction of reactive to passive $\mathrm{Si}$ species upon thermal oxidation, in agreement with the previous observations [47].

In order to further elucidate the influence of pSi oxidation on the dissolution rate, a parallel experiment was set up, where, at specified time points the dissolution was terminated, and the residual pSi particles were collected and examined with FTIR. The infrared spectra (not shown), indicated that once in contact with the aqueous medium, the pSi simultaneously undergoes both dissolution and oxidation. The proposed mechanism for $\mathrm{pSi}$ oxidation in water is oxygen attack of the $\mathrm{Si}-\mathrm{Si}$ backbond, analogous to $\mathrm{pSi}$ oxidation in air [53], where the rate limiting step is oxygen diffusion within the $\mathrm{Si}-\mathrm{Si}$ lattice [44]. From Figure 5a, the observed decrease in absorbance due to $\mathrm{Si}-\mathrm{Si}$ stretching modes (at $615 \mathrm{~cm}^{-1}$ ) and $\mathrm{Si}-\mathrm{H}_{2}$ wagging modes for $\mathrm{pSi}$ samples thermally oxidized at increased temperatures correlates well with the extent (\%) of pSi dissolution observed after $8 \mathrm{~h}$. This highlights the critical dependence of $\mathrm{pSi}$ dissolution on the availability of unoxidized surface hydride species. Similarly, in Figure $5 \mathrm{~b}$, a linear $\left(R^{2}=0.99\right)$ relationship was observed between the integrated absorbance due to $\mathrm{Si}-\mathrm{O}$ stretching and dissolution time. This indicates that oxidation of the pSi particles in the dissolution media follows zero order kinetics. Given that $~ 80 \%$ pSi dissolution was observed in the first $30 \mathrm{~min}$, i.e., when the extent of pSi oxidation remains relatively low, the pSi dissolution was not significantly affected by the concurrent oxidation occurring. 


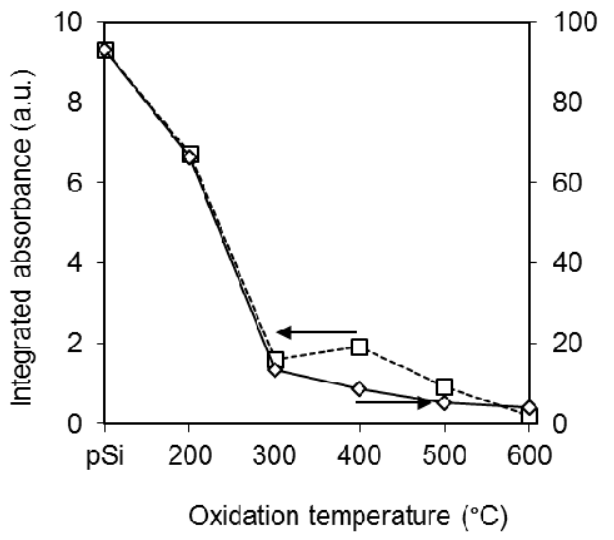

(a)

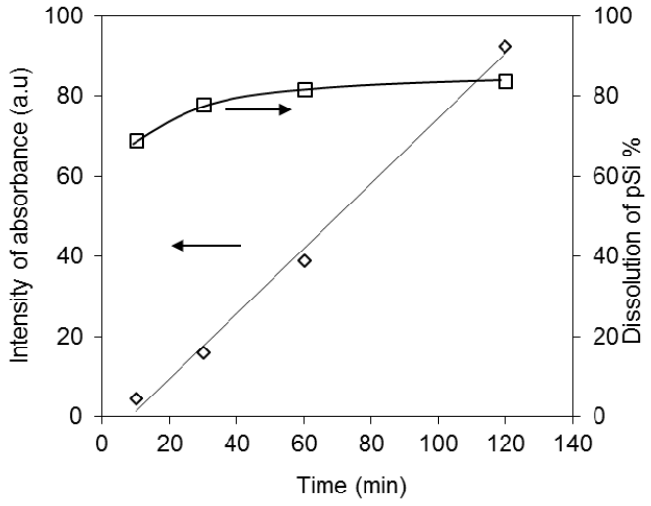

(b)

Figure 5. Correlation of pSi surface chemistry as determined with FTIR and dissolution behavior. (a) Influence of pSi thermal oxidation temperature on the Si-Si stretching modes $\left(615 \mathrm{~cm}^{-1}\right)$ and $\mathrm{Si}-\mathrm{H}_{2}$ wagging modes $\left(660 \mathrm{~cm}^{-1}\right)(\square)$ and dissolution of the pSi after $8 \mathrm{~h}(\diamond)$ and $(\mathbf{b})$ correlating the integrated absorbance due to Si-O symmetric/asymmetric stretching modes $\left(1080 \mathrm{~cm}^{-1}\right)(\diamond)$ with the \% pSi dissolution ( $\square$ ) as a function of dissolution time.

\subsection{Influence of Simulated GI Fluids on pSi Dissolution}

Dissolution kinetics of unoxidized pSi microparticles in simulated gastric fluid (SGF) with/without pepsin are given in Figure 6. The dissolution was independent of pepsin addition during the first two hours when $40 \mathrm{wt} \%$ of pSi dissolved, but reduced at longer times, i.e., $70 \mathrm{wt} \%$ of pSi dissolved at $7 \mathrm{~h}$ in the absence of pepsin and 50\% dissolved in the presence of pepsin. pSi dissolution in SGF was lower than in Tris buffer solution at $\mathrm{pH}$ 7.2, which was expected as the reaction was driven by the nucleophilic attack mechanism of pSi dissolution. The reduced dissolution in the presence of pepsin is considered to be a result of the pepsin protein adsorption on pSi surfaces. Pepsin, a proteolysis enzyme, has a molecular weight $\sim 35 \mathrm{kDa}$ and $\mathrm{pI}=1.0$ [54]; thus, it is neutral in acidic SGF medium. Moreover, the pSi particles undergo oxidation while in an aqueous medium, i.e., they have surface chemistry akin to hydrophilic silica, possessing a small positive charge at $\mathrm{pH}$ 1.0. The pepsin molecule has an estimated hydrodynamic radius of $1.8 \mathrm{~nm}$ [55] and, therefore, likely to penetrate the pSi mesoporous network (pore $\varphi \approx 10 \mathrm{~nm}$ ) in addition to adsorbing at the surface. It has previously been reported that proteins such as albumin, papain, and insulin are able to interact with $\mathrm{pSi}$, as well as being able to penetrate into the porous network [56-58].

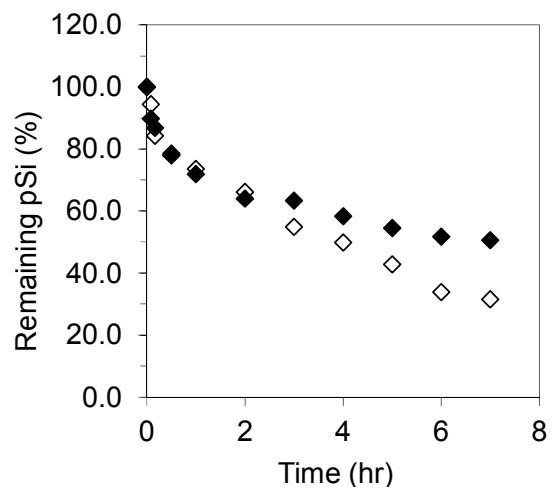

Figure 6. Unoxidised pSi particle dissolution in simulated gastric fluids (SGF) in the presence of pepsin

$(\diamond)$ and absence of pepsin $(\diamond)$.

Dissolution kinetics of unoxidized pSi microparticles in simulated intestinal fluid (SIF) with/without pancreatin are given in Figure 7. In the absence of pancreatin, i.e., phosphate buffer solution $(0.05 \mathrm{M})$ at $\mathrm{pH} 6.8, \mathrm{pSi}$ exhibited fast dissolution, which accounts for $64 \mathrm{wt} \%$ of its initial mass, 
compared to $90 \mathrm{wt} \%$ in Tris buffer solution at $\mathrm{pH} 7.2$ in the first one hour. The difference between pSi dissolution in these two buffer solutions is attributed to their specific components since their $\mathrm{pH}$ values were similar. The primary amine moiety in tris(hydroxymethyl)aminomethane $\left(\mathrm{NH}_{2} \mathrm{C}\left(\mathrm{CH}_{2} \mathrm{OH}\right)_{3}\right)$ from Tris buffer might act as a catalyst to hydrolyze surface hydrides of pSi, such catalytic effects of organic amines on pSi hydrolysis were observed previously [34].

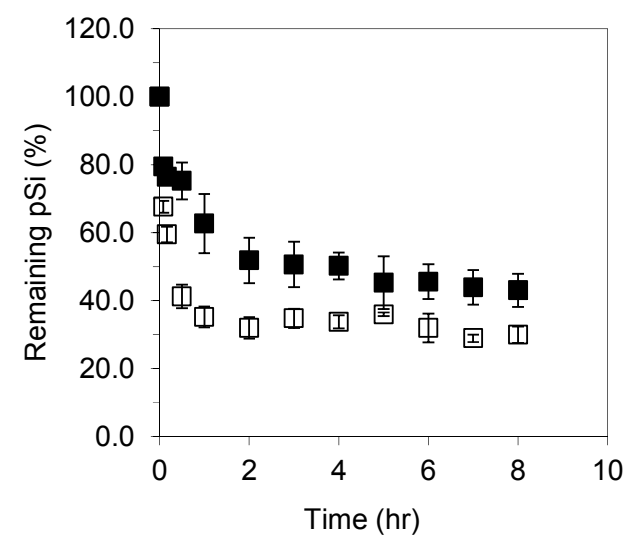

Figure 7. pSi dissolution in simulated intestinal fluids (SIF) in the presence ( $\square$ ) and absence ( $\square$ ) of pancreatin (\% \pm s.d., $n=2)$.

In the presence of pancreatin, fast dissolution was observed in the first $2 \mathrm{~h}$, with $\sim 50 \%$ of the initial mass dissolved; this was lower than that without pancreatin. Pancreatin is a mixture of the digestive enzymes including trypsin $(\mathrm{MW}=23.3 \mathrm{kDa}, \mathrm{pI}=10.1-10.5)$, amylase $(\mathrm{MW}=50-55 \mathrm{kDa}, \mathrm{pI}=\sim 6)$ and lipase $(\mathrm{MW}=46 \mathrm{kDa}, \mathrm{pI}=7.4)$ [59]. At neutral $\mathrm{pH}$, trypsin is positively charged, therefore it can undergo electrostatic interactions with the negatively charged unoxidised pSi surface. In contrast, the amylase and lipase molecules are neutral, therefore will only be able to adsorb via weak interactions such as van der Waals forces.

\section{Discussion}

pSi dissolution (as described in Equations (1) and (2)) occurs via a nucleophilic substitution mechanism. Given that the dissolution media volume was far in excess of the sample mass, it can be assumed that pSi dissolution follows pseudo-first order kinetics. However, this was shown not to be the case since a plot of semi-log pSi \% remaining versus time data was not linear (data not shown), and more complex kinetics are apparent. The pSi surface is comprised of monohydrides, dihydrides, and trihydrides, each with highly varied activities in aqueous solution. As reported in the literature, the reaction of a vertical dihydride site is five times faster than a terrace monohydride, but two times slower than a kink site (a distorted monohydride) [28]. In addition, dangling bonds might be formed from breaking Si crystalline lattices due to grinding/milling processes. Dangling bonds possess a lower activation barrier for reaction due to lone pair electrons, which are susceptible to water attack [60]. It is assumed that each of the surface species reacted with water at different rates.

The presence of various reaction sites and the parallel oxidation processes result in more complex dissolution kinetics. The total silicic acid is better described as a sum of silicic acid from each surface species reacted with water. Thus, for the reaction of a surface species, with respect to silicic acid,

$$
C_{t}=A_{\infty}\left(1-e^{k_{a} t}\right)
$$

where $k$ is the rate constant $C_{t}, A_{\infty}$ and $B_{\infty}$ are concentration of silicic acid at time, $t$ and $\infty$.

$$
C_{t}=A_{\infty}\left(1-e^{k_{a} t}\right)+B_{\infty}\left(1-e^{k_{b} t}\right)
$$


For the total silicic acid from sample;

$$
C_{\infty}=A_{\infty}+B_{\infty}
$$

Thus, Equation (3) can be combined with Equation (5) in a natural logarithmic form

$$
\begin{gathered}
\ln \left(\frac{C_{\infty}-C_{t}}{C_{\infty}}\right)=\ln \left[\frac{A_{\infty}}{\left(A_{\infty}+B_{\infty}\right)} \cdot e^{-k_{f} t}+\frac{A_{\infty}}{\left(A_{\infty}+B_{\infty}\right)} \cdot e^{-k_{s} t}\right] \\
=\ln \left(P_{f} \cdot e^{-k_{f} t}+P_{S} \cdot e^{-k_{s} t}\right)
\end{gathered}
$$

where $P$ indicates the relative fraction of fast $\left(P_{f}\right)$ and slow $\left(P_{s}\right)$ dissolving species, and $P_{f}+P_{s}=1$.

This multi-exponential (or the sum of exponential model) approach was used by Truesdale et al. to describe biosilica dissolution data [61]. The model fit agreed well with the postulation that the total surface of biosilica arose from two separate fractions, fast-dissolving and slow-dissolving. However, in the current study, the best linear regression from fitting a simple exponential model to the full dissolution data of unoxidized and oxidized at $200{ }^{\circ} \mathrm{C}$ suggested the pSi surface consisted of three separate fractions, fast-, medium- and slow-dissolving surface species (reactive sites). The parameters obtained from this data fit are summarized in Table 2. Therefore:

$$
\ln \left(\frac{C_{\infty}-C_{t}}{C_{\infty}}\right)=\ln \left(P_{f} \cdot e^{-k_{f} t}+P_{m} \cdot e^{-k_{m} t}+P_{S} \cdot e^{-k_{s} t}\right)
$$

where $P_{f}+P_{m}+P_{s}=1$. The left term in Equation (7) is equivalent to the ratio of the remaining pSi on the assumptions that (a) pSi will be completely converted to silicic acid at infinity time, and (b) there is no side reaction nor reverse reaction, and silicic acid is the only product. This is rational according to the reaction mechanism described earlier since all surface hydrides react with water to form silicic acid, a new layer of hydride would be reconstructed and ready to next cycle of reactions.

Table 2. Parameters from fitting multi-exponential equation to dissolution of unoxised and $200{ }^{\circ} \mathrm{C}$ oxidized pSi particles.

\begin{tabular}{ccccccc}
\hline \multirow{2}{*}{ Sample } & \multicolumn{3}{c}{ Unoxidized pSi } & \multicolumn{3}{c}{ OXpSi-200 } \\
\cline { 2 - 6 } & Fast & Medium & Slow & Fast & Medium & Slow \\
\hline Rate constant $k\left(\mathrm{~h}^{-1}\right)$ & 6.82 & 0.19 & 0.0475 & 2.05 & 0.463 & 0.00824 \\
Fraction $(\mathrm{P})$ & 0.690 & 0.155 & 0.155 & 0.340 & 0.240 & 0.420 \\
Time points & $0-10 \mathrm{~min}$ & $10-240 \mathrm{~min}$ & $360 \mathrm{~min}-24 \mathrm{~h}$ & $0-10 \mathrm{~min}$ & $10-60 \mathrm{~min}$ & $360 \mathrm{~min}-48 \mathrm{~h}$ \\
$R^{2}$ & $1.0 *$ & 0.9673 & 0.9944 & $1.0 *$ & 0.9951 & 0.9217 \\
\hline
\end{tabular}

As shown in Table 2, the fast fraction of dissolutions from both the pSi samples consists of only two data points (from time zero to $10 \mathrm{~min}$ ) when pSi dissolved extremely fast and accounted about $69 \%$ and $24 \%$ of the samples' dissolution (estimated from the intercept of linear regression), respectively. The dissolved sample mass and rate constant from pSi are three times higher than from OXpSi-200. The fractions of the medium and slow dissolution phases from the unoxidized pSi are equivalent, i.e., $15.5 \%$ and these two fractions from pSi oxidized at $200{ }^{\circ} \mathrm{C}$ were about two times higher than the fast one. In contrast, the remaining 31\% of pSi dissolved slowly (slower than dissolution of the second fraction from $200^{\circ} \mathrm{C}$ ). These regions of slow dissolution were likely due to oxidation of pSi that has taken place concurrently during dissolution.

The third fraction from OXpSi-200 accounts for $44 \%$ of the sample mass, which dissolved with a rate constant similar to those of pSi oxidized at 300 and $400{ }^{\circ} \mathrm{C}$. The difference between dissolution observed from OXpSi-200 and pSi clearly indicated changes in their physicochemical properties. First, oxidation has eliminated the highly reactive dangling bonds and trihydrides (only one $\mathrm{Si}-\mathrm{Si}$ backbond attached), which contributes to the initial fast dissolution phase. This is in agreement with the observation from the study of heat annealing of a silicon wafer, from which the number of dangling 
bonds decreased significantly at $200{ }^{\circ} \mathrm{C}$ [62], while the surface hydrides from a hydrogen passivated silicon wafer were showed to be relatively stable [63]. Secondly, $\sim 42 \%$ of OXpSi-200 has a similar oxidation state to OXpSi-300 and $\mathrm{OXpSi}-400$, confirming the impact of temperature to pSi oxidation.

The fits from the simulated data calculated from Equation (7) using the variables given in Table 2 are presented in Figure 8. For both the data sets, the simulation data did not fit precisely, i.e., the predicted fraction of slow dissolution from $\mathrm{pSi}$ and the medium dissolution phase from OXpSi-200 deviated from the observed experimental data. A better fit with adjusted variables for $\mathrm{pSi}$ (dash line) was achieved if $k_{\mathrm{m}}=0.4 \mathrm{~h}^{-1}$, which is double the original value. Similarly, better fitting for the OXpSi-200 data (dash line), was achieved with $k_{\mathrm{m}}=0.92 \mathrm{~h}^{-1}$ and the fractions of medium and slow reactions, $P_{\mathrm{m}}=0.28$ and $P_{\mathrm{s}}=0.38$. For pSi dissolution, including the $24 \mathrm{~h}$ point was the major attribute to the underestimated rate constant (N.B. without $24 \mathrm{~h}$ point, $k_{\mathrm{s}}=0.107 \mathrm{~h}^{-1}$ ). After $8 \mathrm{~h}, \sim 90 \%$ of $\mathrm{pSi}$ dissolved, generating a silicic acid concentration of $\sim 3.2 \mathrm{mM}$, i.e., just above its saturated concentration $\left(2 \mathrm{mM}\right.$ at $\left.40^{\circ} \mathrm{C}\right)$. The consequent polymerization of silicic acid could decrease the rate of pSi dissolution. For OXpSi-200, the fraction of slow reaction included $\sim 30 \%$ of the total sample mass of undissolved $\mathrm{pSi}$, which might cause overestimated dissolution.

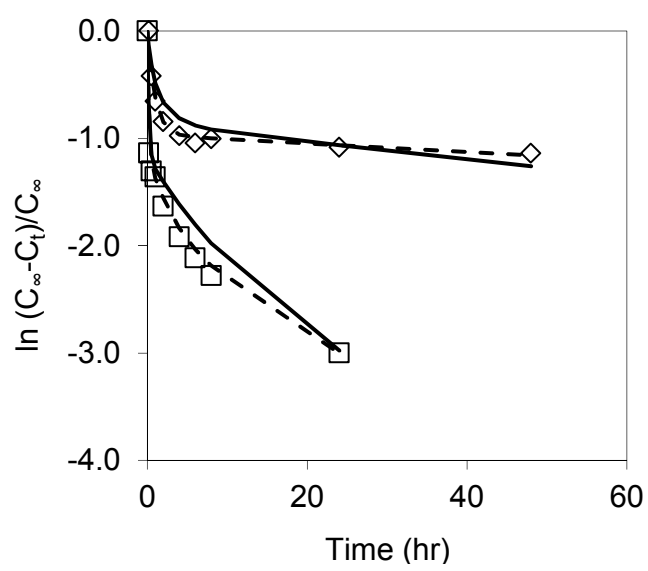

Figure 8. Fitting of simulated data (solid lines) obtained with the sum of exponentials model (Equation (7)) and with adjusted variables (dash lines) over the plots of $\ln \left(C_{\infty}-C_{t}\right) / C_{\infty}$ versus time

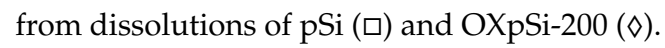

Dissolution kinetics of the pSi samples oxidized at $\geq 300^{\circ} \mathrm{C}$ are presented in Figure 9, with all data sets exhibiting good linearity from the semi-log concentration-time plots, confirming a simple exponential model (fit and rate constant are shown in Table 3). This suggests that the thermally oxidized $\left(>300^{\circ} \mathrm{C}\right) \mathrm{pSi}$ possesses a more homogeneous surface, i.e., a uniformity of surface species or reaction sites, as confirmed by FTIR.

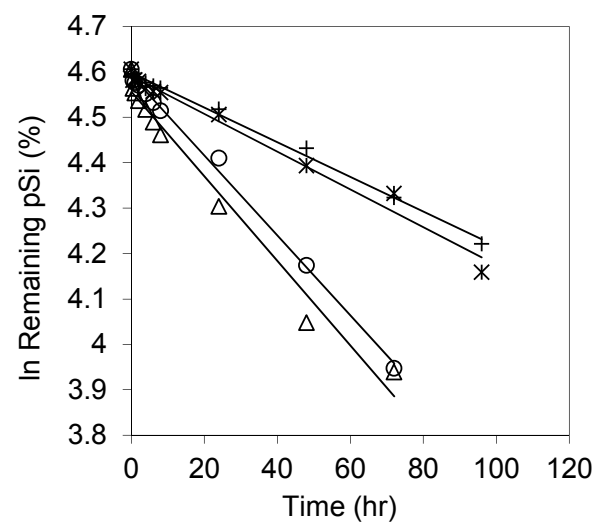

Figure 9. Plots of semi-log the remaining pSi \% versus time and least square fittings to the data of dissolution of pSi samples oxidized at above $300{ }^{\circ} \mathrm{C}$. The parameters are given in Table 3 . 
Table 3. The parameters obtained from applying least square to plot of logarithmic $\%$ remaining sample versus time from dissolutions of pSi particles oxidized at $\geq 300^{\circ} \mathrm{C}$.

\begin{tabular}{cccc}
\hline Sample & Rate Constant $\left(\times \mathbf{1 0}^{-\mathbf{3}} \mathbf{h}^{-\mathbf{1}}\right)$ & $\boldsymbol{t}_{\frac{1}{2}}(\mathbf{h})$ & $\boldsymbol{R}^{\mathbf{2}}$ \\
\hline OXpSi-300 & 9.300 & 74.5 & 0.9778 \\
OXpSi-400 & 8.797 & 78.8 & 0.9967 \\
OXpSi-500 & 4.153 & 166.9 & 0.9823 \\
OXpSi-600 & 3.811 & 181.8 & 0.9951 \\
\hline
\end{tabular}

A positive correlation between the dissolution rate constant and surface properties (IR absorption) of pSi was demonstrated in Figure 10. The rate constant of dissolution decreased when oxidation temperature increased, and this is consistent with decreasing intensities of $\mathrm{Si}-\mathrm{Hx}$ and Si-Si. The IR absorption band of $\mathrm{Si}-\mathrm{Hx}$ disappeared at $300{ }^{\circ} \mathrm{C}$ while the intensity of $\mathrm{Si}-\mathrm{Si}$ absorption decreased dramatically from 200 to $300^{\circ} \mathrm{C}$. Furthermore, the IR absorbances due to the hydrides whose backbonds were oxidized (OSi-Hx) increased sharply. From $300{ }^{\circ} \mathrm{C}$, this band decreased gradually along with the increase of temperature and eventually disappeared at $600^{\circ} \mathrm{C}$. From our surface characterization studies we know that at $200^{\circ} \mathrm{C}$, there are surface hydrides in their intermediate oxidation states, i.e., $\mathrm{Si}$ atoms bonded to one, two, or three oxygen atoms. At $300{ }^{\circ} \mathrm{C}$, only the oxidized hydrides remained. Breaking Si-O-Si bonds, in fact, share the same mechanism as breaking $\mathrm{Si-Si}$ bonds in pSi dissolution, i.e., a nucleophilic substitute with $\mathrm{OH}^{-}$ions $[64,65]$.

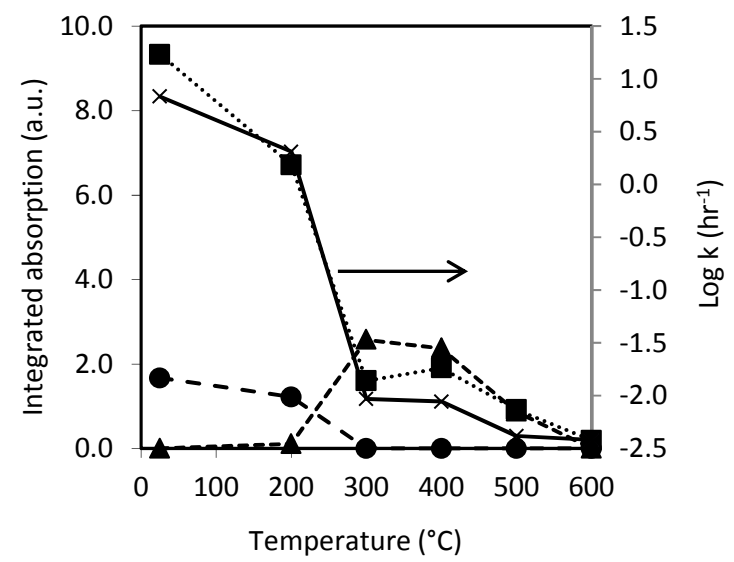

Figure 10. A comparison of rate constants for dissolution and the integrated IR absorption intensity for pSi samples that were oxidized at various temperatures. The temperature for native pSi was set at $25^{\circ} \mathrm{C}$ as a symbolic temperature. Absorption at $615 \mathrm{~cm}^{-1}$ due to $\mathrm{Si}-\mathrm{Si}$ (घ, dot line), at $2025-2150 \mathrm{~cm}^{-1}$ due to $\mathrm{Si}-\mathrm{Hx}\left(\bullet\right.$, dash line) and at $2150-2325 \mathrm{~cm}^{-1}$ due to OSi-Hx ( $\mathbf{\Lambda}$, short dash line), and rate constant, $k$, (corresponds to the right $\mathrm{Y}$ axis) $(\times$, solid line). The values of rate constant for pSi and OXpSi-200 were from the fast dissolution phase.

Our dissolution data showed that the fast dissolution fraction of $\mathrm{pSi}$ oxidized at $200^{\circ} \mathrm{C}$, which predominantly is due to surface hydrides ( $\mathrm{Si}-\mathrm{SiHx}$ ) was 1000 times faster than the dissolution of pSi oxidized at $300^{\circ} \mathrm{C}$, which consists of oxidized hydrides ( $\mathrm{Si}-\mathrm{O}-\mathrm{SiHx}$ ). Dissolution of pSi samples oxidised at $\geq 300{ }^{\circ} \mathrm{C}$ were similar, because all the surface hydrides were in various intermediate oxidation states, to release a $\mathrm{Si}$ atom (in silicic acid form), i.e., breaking not only $\mathrm{Si}-\mathrm{Si}$ bonds but also breaking the newly forming $\mathrm{Si}-\mathrm{O}-\mathrm{Si}$ backbonds which becomes a rate-limiting step for the $\mathrm{pSi}$ dissolution. Also, it is worthy of note that the formation of $\mathrm{Si}-\mathrm{O}-\mathrm{Si}$ bonds due to thermal oxidation can cause geometric changes of the $\mathrm{pSi}$ lattice resulting in both negative and positive impacts to dissolution. In the former case, expanded crystalline lattice results in reduced surface area and pore volume [66]; while in the latter, strain and deformation of lattice would be in favor of dissolution [67]. 


\section{Conclusions}

The dissolution kinetics of $\mathrm{pSi}$ microparticles can be extensively controlled by thermal oxidation (200-600 ${ }^{\circ} \mathrm{C}$ ). Unoxidized pSi and OXpSi-200 dissolved fastest at pH 7.2, which was attributed to the presence of the different surface hydride groups which exhibit different reaction rates. Thermal oxidation has a significant impact on the pSi dissolution mechanism, and $\mathrm{pSi}$ oxidized at above $300{ }^{\circ} \mathrm{C}$ following pseudo-first order dissolved kinetics, this is due to the rate-limiting step of breaking oxidized backbonds ( $\mathrm{Si}-\mathrm{O}-\mathrm{Si}$ ). We have successfully developed an exponential kinetic model to describe $\mathrm{pSi}$ dissolution, which accounts for the influence of Si speciation. Finally, we investigated the influence of simulated gastric and intestinal fluids on unoxidized $\mathrm{pSi}$ dissolution, and showed the presence of GI proteins reduces $\mathrm{pSi}$ dissolution; this is presumed do to surface adsorption to $\mathrm{pSi}$ and protection against water attack of the Si surface species. These findings provide insight into key considerations for future formulation optimization of specific pSi based biomaterials, particularly for their use in oral drug delivery.

Author Contributions: Conceptualization, C.A.P. and T.J.B.; methodology, F.W.; validation, F.W.; formal analysis, F.W.; investigation, F.W.; data curation, C.P.; writing-original draft preparation, F.W..; writing-review and editing, T.J.B. and C.A.P.; supervision, T.J.B. and C.A.P.; project administration, C.A.P.; funding acquisition, C.A.P.

Funding: This research was funded by an Australian Research Council (ARC) Linkage grant (LP0562379).

Acknowledgments: This work formed part of Feng (Frank) Wang's PhD thesis, entitled "Porous Silicon as a Delivery System for Poorly Soluble Drugs". Sadly, Feng Wang passed away unexpectedly in 2017, while undertaking a Postdoctoral Fellowship at Monash University (Victoria, Australia).

Conflicts of Interest: The authors declare no conflict of interest.

\section{References}

1. Canham, L.T. Bioactive silicon structure fabrication through nanoetching techniques. Adv. Mater. 1995, 7, 1033-1037. [CrossRef]

2. Korhonen, E.; Rönkkö, S.; Hillebrand, S.; Riikonen, J.; Xu, W.; Järvinen, K.; Lehto, V.-P.; Kauppinen, A. Cytotoxicity assessment of porous silicon microparticles for ocular drug delivery. Eur. J. Pharm. Biopharm. 2016, 100, 1-8. [CrossRef]

3. Tzur-Balter, A.; Shatsberg, Z.; Beckerman, M.; Segal, E.; Artzi, N. Mechanism of erosion of nanostructured porous silicon drug carriers in neoplastic tissues. Nat. Commun. 2015, 6, 1-8. [CrossRef] [PubMed]

4. Maniya, N.H.; Patel, S.R.; Murthy, Z.V.P. Development and in vitro evaluation of acyclovir delivery system using nanostructured porous silicon carriers. Chem. Eng. Res. Des. 2015, 104, 551-557. [CrossRef]

5. Wang, F.; Hui, H.; Barnes, T.J.; Barnett, C.; Prestidge, C.A. Oxidized Mesoporous Silicon Microparticles for Improved Oral Delivery of Poorly Soluble Drugs. Mol. Pharm. 2009, 7, 227-236. [CrossRef]

6. Qi, S.C.; Zhang, P.; Ma, M.; Yao, M.; Wu, J.; Mäkilä, E.; Salonen, J.; Ruskoaho, H.; Xu, Y.; Santos, H.A.; et al. Cellular Internalization-Induced Aggregation of Porous Silicon Nanoparticles for Ultrasound Imaging and Protein-Mediated Protection of Stem Cells. Small 2019, 15, 13. [CrossRef]

7. Galushka, V.V.; Belobrovaya, O.Y.; Bratashov, D.N.; Kondrateva, O.Y.; Polyanskaya, V.P.; Sidorov, V.I.; Yagudin, I.T.; Terin, D.V. Gamma-Radiation Monitoring of Luminescent Porous Silicon for Tumor Imaging. Bionanoscience 2018, 8, 818-822. [CrossRef]

8. Yang, Y.; Su, P.; Tang, Y. Stimuli-Responsive Lanthanide-Based Smart Luminescent Materials for Optical Encoding and Bio-applications. ChemNanoMat 2018, 4, 1097-1120. [CrossRef]

9. Kumeria, T.; McInnes, S.J.P.; Maher, S.; Santos, A. Porous silicon for drug delivery applications and theranostics: Recent advances, critical review and perspectives. Expert Opin. Drug Deliv. 2017, 14, 1407-1422. [CrossRef]

10. Barnes, T.J.; Prestidge, C.A. Recent advances in porous silicon-based therapeutic delivery. Ther. Deliv. 2015, 6, 97-100. [CrossRef]

11. Jakobsson, U.; Makila, E.; Airaksinen, A.J.; Alanen, O.; Etile, A.; Koster, U.; Ranjan, S.; Salonen, J.; Santos, H.A.; Helariutta, K. Porous Silicon as a Platform for Radiation Theranostics Together with a Novel RIB-Based Radiolanthanoid. Contrast Media Mol. Imaging 2019, 2019, 1-9. [CrossRef] [PubMed] 
12. Wang, C.-F.; Sarparanta, M.P.; Mäkilä, E.M.; Hyvönen, M.L.K.; Laakkonen, P.M.; Salonen, J.J.; Hirvonen, J.T.; Airaksinen, A.J.; Santos, H.A. Multifunctional porous silicon nanoparticles for cancer theranostics. Biomaterials 2015, 48, 108-118. [CrossRef] [PubMed]

13. Prestidge, C.A.; Barnes, T.J. 15-Nanoporous silicon to enhance drug solubility. In Porous Silicon for Biomedical Applications; Santos, H.A., Ed.; Woodhead Publishing: Cambridge, UK, 2014; pp. 356-373.

14. Merazga, S.; Cheriet, A.; M'Hammedi, K.; Mefoued, A.; Gabouze, N. Investigation of porous silicon thin films for electrochemical hydrogen storage. Int. J. Hydrogen Energy 2019, 44, 9994-10002. [CrossRef]

15. Tang, C.-H.; Li, W.-J.; Hung, C.-H.; Hsiao, P.-H.; Chen, C.-Y. Highly Porous Silicon Nanowires Made with Solvent-Mediated Wet Chemical Etching and Their Thermoelectric Applications. ChemistrySelect 2017, 2, 10865-10870. [CrossRef]

16. Xia, B.; Zhang, W.; Shi, J.; Li, J.; Chen, Z.; Zhang, Q. NIR light-triggered gelling in situ of porous silicon nanoparticles/PEGDA hybrid hydrogels for localized combinatorial therapy of cancer cells. J. Appl. Polym. Sci. 2019, 136, 7. [CrossRef]

17. Kurdyukov, D.A.; Eurov, D.A.; Shmakov, S.V.; Kirilenko, D.A.; Kukushkina, J.A.; Smirnov, A.N.; Yagovkina, M.A.; Klimenko, V.V.; Koniakhin, S.V.; Golubev, V.G. Fabrication of doxorubicin-loaded monodisperse spherical micro-mesoporous silicon particles for enhanced inhibition of cancer cell proliferation. Microporous Mesoporous Mater. 2019, 281, 1-8. [CrossRef]

18. Kang, R.H.; Lee, S.H.; Kang, S.; Kang, J.; Hur, J.K.; Kim, D. Systematic Degradation Rate Analysis of Surface-Functionalized Porous Silicon Nanoparticles. Materials 2019, 12, 580. [CrossRef]

19. Li, W.; Liu, Z.H.; Fontana, F.; Ding, Y.P.; Liu, D.F.; Hirvonen, J.T.; Santos, H.A. Tailoring Porous Silicon for Biomedical Applications: From Drug Delivery to Cancer Immunotherapy. Adv. Mater. 2018, 30, 1703740. [CrossRef]

20. Seo, H.; Kim, D.; Ahn, H.S.; Hwang, S.; Luu, Q.S.; Kim, J.; Lee, S.; Lee, Y. Efficient Conversion Method of Bulk Silicon Powders into Porous Silicon Nanoparticles. Bull. Korean Chem. Soc. 2018, 39, 1455-1458. [CrossRef]

21. Jarvis, K.L.; Barnes, T.J.; Prestidge, C.A. Surface chemistry of porous silicon and implications for drug encapsulation and delivery applications. Adv. Colloid Interface Sci. 2012, 175, 25-38. [CrossRef]

22. Jarvis, K.L.; Barnes, T.J.; Prestidge, C.A. Surface chemical modification to control molecular interactions with porous silicon. J. Colloid Interface Sci. 2011, 363, 327-333. [CrossRef] [PubMed]

23. Jarvis, K.L.; Barnes, T.J.; Prestidge, C.A. Thermal Oxidation for Controlling Protein Interactions with Porous Silicon. Langmuir 2010, 26, 14316-14322. [CrossRef] [PubMed]

24. Mäkilä, E.; Bimbo, L.M.; Kaasalainen, M.; Herranz, B.; Airaksinen, A.J.; Heinonen, M.; Kukk, E.; Hirvonen, J.; Santos, H.A.; Salonen, J. Amine Modification of Thermally Carbonized Porous Silicon with Silane Coupling Chemistry. Langmuir 2012, 28, 14045-14054. [CrossRef] [PubMed]

25. Britcher, L.; Barnes, T.J.; Griesser, H.J.; Prestidge, C.A. PEGylation of porous silicon using click chemistry. Langmuir 2008, 24, 7625-7627. [CrossRef] [PubMed]

26. Zhang, D.X.; Yoshikawa, C.; Welch, N.G.; Pasic, P.; Thissen, H.; Voelcker, N.H. Spatially Controlled Surface Modification of Porous Silicon for Sustained Drug Delivery Applications. Sci. Rep. 2019, 9, 11. [CrossRef] [PubMed]

27. Ogata, Y.H.; Kato, F.; Tsuboi, T.; Sakka, T. Changes in the environment of hydrogen in porous silicon with thermal Annealing. J. Electrochem. Soc. 1998, 145, 2439-2444. [CrossRef]

28. Hines, M.A.; Chabal, Y.J.; Harris, T.D.; Harris, A.L. Measuring the structure of etched silicon surfaces with Raman spectroscopy. J. Chem. Phys. 1994, 101, 8055. [CrossRef]

29. Allongue, P.; Brune, H.; Gerischer, H. In situ STM observations of the etching of n-Si(111) in NaOH solutions. Surf. Sci. 1992, 275, 414-423. [CrossRef]

30. Campbell, S.A.; Schiffrin, D.J.; Tufton, P.J. Chemical and electrochemical anisotropic dissolution of silicon in ethylenediamine + pyrocatechol + water media. J. Electroanal. Chem. 1993, 344, 211-233. [CrossRef]

31. Steinem, C.; Janshoff, A.; Lin, V.S.Y.; Volcker, N.H.; Ghadiri, R.M. DNA hybridization-enhanced porous silicon corrosion: Mechanistic investigations and prospect for optical interferometric biosensing. Tetrahedron 2004, 60, 11259-11267. [CrossRef]

32. Zhu, G.; Liu, J.-T.; Wang, Y.; Zhang, D.; Guo, Y.; Tasciotti, E.; Hu, Z.; Liu, X. In Situ Reductive Synthesis of Structural Supported Gold Nanorods in Porous Silicon Particles for Multifunctional Nanovectors. ACS Appl. Mater. Interfaces 2016, 8, 11881-11891. [CrossRef] [PubMed] 
33. Bateman, J.E.; Eagling, R.D.; Horrocks, B.R.; Houlton, A.; Worrall, D.R. Role for organic molecules in the oxidation of porous silicon. Chem. Commun. 1997, 23, 2275-2276. [CrossRef]

34. Xu, D.; Sun, L.; Li, H.; Zhang, L.; Guo, G.; Zhao, X.; Gui, L. Hydrolysis and silanization of the hydrosilicon surface of freshly prepared porous silicon by an amine catalytic reaction. New J. Chem. 2003, 27, 300-306. [CrossRef]

35. Floch, J.; Blain, S.; Birot, D.; Treguer, P. In situ determination of silicic acid in sea water based on FIA and colorimetric dual-wavelength measurements. Anal. Chim. Acta 1998, 377, 157-166. [CrossRef]

36. Anderson, S.H.C.; Elliott, H.; Wallis, D.J.; Canham, L.T.; Powell, J.J. Dissolution of different forms of partially porous silicon wafers under simulated physiological conditions. Phys. Status Solidi 2003, 197, 331-335. [CrossRef]

37. Manchon, A.; Alkhraisat, M.H.; Rueda-Rodriguez, C.; Pintado, C.; Prados-Frutos, J.C.; Torres, J.; Cabarcos, E.L. Silicon bioceramic loaded with vancomycin stimulates bone tissue regeneration. J. Biomed. Mater. Res. Part $B$ Appl. Biomater. 2018, 106, 2307-2315. [CrossRef]

38. Low, S.P.; Voelcker, N.H.; Canham, L.T.; Williams, K.A. The biocompatibility of porous silicon in tissues of the eye. Biomaterials 2009, 30, 2873-2880. [CrossRef]

39. Bowditch, A.P.; Waters, K.; Gale, H.; Rice, P.; Scott, E.A.M.; Canham, L.T.; Reeves, C.L.; Loni, A.; Cox, T.I. In-vivo assessment of tissue compatibility and calcification of bulk and porous silicon. Mater. Res. Soc. Symp. Proc. 1999, 536, 149. [CrossRef]

40. Wang, F.; Timothy, J.B.; Clive, A.P. Celecoxib confinement within mesoporous silicon for enhanced oral bioavailability. Mesoporous Biomater. 2013, 1, 1-15. [CrossRef]

41. Kato, Y.; Ito, T.; Hirak, A. Initial oxidation process of anodized porous silicon with hydrogen atoms chemisorbed on the inner surface Japan. J. Appl. Phys. 1988, 27, L1406. [CrossRef]

42. Ogata, Y.; Niki, H.; Sakka, T.; Iwasaki, M. Oxidation of porous silicon under water vapor environment. J. Electrochem. Soc. 1995, 142, 1595-1601. [CrossRef]

43. Bateman, J.E.; Horrocks, B.R.; Houlton, A. Reactions of water and methanol at hydrogen-terminated silicon surfaces studied by transmission FTIR. J. Chem. Soc. Faraday Trans. 1997, 93, 2427-2431. [CrossRef]

44. Haiss, W.; Raisch, P.; Schirin, D.J.; Bitsch, L.; Nichols, R.J. An FTIR study of the surface chemistry of the dynamic $\mathrm{Si}(100)$ surface during etching in alkaline solution. Faraday Discuss 2002, 121, 167-180. [CrossRef] [PubMed]

45. Chabal, Y.J.; Raghavachari, K. New ordered structure for the H-Saturated Si(100) surface: The (3x1) Phase. Phys. Rev. Lett. 1985, 54, 1055. [CrossRef] [PubMed]

46. Bellet, D.; Dolino, G.; Ligeon, M.; Blanc, P.; Krisch, M. Studies of coherent and diffuse x-ray scattering by porous silicon. J. Appl.Phys. 1992, 71, 145-149. [CrossRef]

47. Mawhinney, D.B.; Glass, J.A.; Yates, J.T. FTIR study of the oxidation of porous silicon. J. Phys. Chem. B 1997, 101, 1202-1206. [CrossRef]

48. Kato, Y.; Ito, T.; Hiraki, A. Low temperature oxidation of crystalline porous silicon. Appl. Surf. Sci. 1989, 41-42, 614-618. [CrossRef]

49. Graf, D.; Grundner, M.; Schulz, R. Reaction of water with hydrofluoric acid treated silicon(111) and (100) surfaces. J. Vac. Sci.Tech. A 1989, 7, 808-813. [CrossRef]

50. Stefanov, B.B.; Gurevich, A.B.; Weldon, M.K.; Raghavachari, K.; Chabal, Y.J. Silicon Epoxide: Unexpected Intermediate during Silicon Oxide Formation. Phys. Rev. Lett. 1998, 81, 3908. [CrossRef]

51. Ogata, Y.H.; Tsuboi, T.; Sakka, T.; Naito, S. Oxidation of porous silicon in dry and wet environments under mild temperature conditions. J. Porous Mater. 2000, 7, 63-66. [CrossRef]

52. Raghavachari, K. First-Principles quantum chemical investigations of silicon oxidation. In Fundamental Aspect of Silicon Oxidation; Chabal, Y.J., Ed.; Springer: Berlin/Heidelberg, Germany, 2001; pp. 127-141.

53. Morita, M.; Ohmi, T.; Hasegawa, E.; Kawakami, M.; Suma, K. Control factor of native oxide growth on silicon in air or in ultra-pure water. Appl. Phys. Lett. 1989, 55, 562-564. [CrossRef]

54. Gole, A.; Sastry, M.; Dash, C.; Rao, M. Encapsulation and biocatalytic activity of the enzyme pepsin in fatty lipid films by selective electrostatic interactions. Chem. Commun. 2000, 4, 297-298. [CrossRef]

55. Uversky, V.N.; Permyakov, A.E.A. Methods in Protein Structure and Stability Analysis: Conformational Stability, Size, Shape and Surface of Protein Molecules. In Molecular Anatomy and Physiology of Protein; Uversky, V.N., Ed.; Nova Publishers: Hauppauge, NY, USA, 2007; p. 404. 
56. Prestidge, C.A.; Barnes, T.J.; Mierczynska-Vasilev, A.; Skinner, W.; Peddie, F.; Barnett, C. Loading and release of a model protein from porous silicon powders. Phys. Status Solidi A Appl. Mater. Sci. 2007, 204, 3361-3366. [CrossRef]

57. Foraker, A.B.; Walczak, R.J.; Cohen, M.H.; Boiarski, T.A.; Grove, C.F.; Swaan, P.W. Microfabricated porous silicon particles enhance paracellular delivery of insulin across intestinal Caco-2 cell monolayers. Pharm. Res. 2003, 20, 110-116. [CrossRef]

58. Karlsson, L.M.; Tengvall, P.; Lundstrom, I.; Arwin, H. Penetration and loading of human serum albumin in porous silicon layers with different pore sizes and thicknesses. J. Colloid Interface Sci. 2003, 266, 40-47. [CrossRef]

59. Cozzone, P.; Pasero, L.; Marchis-Mouren, G. Characterization of Porcine Pancreatic Isoamylases: Separation and Amino Acid Composition. Biochim. Biophys. Acta 1970, 200, 590. [CrossRef]

60. Bozso, F.; Avouris, P. Reaction of $\mathrm{Si}(100)$ with $\mathrm{NH}_{3}$ : Rate-limiting steps and reactivity enhancement via electronic excitation. Phys. Rev. Lett. 1986, 57, 1185. [CrossRef]

61. Truesdale, V.; Greenwood, J.; Rendell, A. The rate-equation for biogenic silica dissolution in seawater-New hypotheses. Aquat. Geochem. 2005, 11,319-343. [CrossRef]

62. Lim, P.K.; Tam, W.K.; Yeung, L.F.; Lam, F.M. Effect of hydrogen on dangling bond in a-Si thin film. J. Phys. Conf. Ser. 2007, 61, 708. [CrossRef]

63. Trucks, G.W.; Raghavachari, K.; Higashi, G.S.; Chabal, Y.J. Mechanism of HF etching of silicon surfaces: A theoretical understanding of hydrogen passivation. Phys. Rev. Lett. 1990, 65, 504. [CrossRef]

64. O'Connor, T.L.; Greenberg, S.A. The kinetics for the solution of silica in aqueous solutions. J. Phys. Chem. 1958, 62, 1195-1198.

65. Bunker, B.C. Molecular mechanisms for corrosion of silica and silicate glasses. J. Non-Cryst. Solid 1994, 179, 300-308. [CrossRef]

66. Jarvis, K.L.; Barnes, T.J.; Badalyan, A.; Pendleton, P.; Prestidge, C.A. Impact of thermal oxidation on the adsorptive properties and structure of porous silicon particles. J. Phys. Chem. C 2008, 112, 9717-9722. [CrossRef]

67. Pap, A.E.; Kordas, K.; Toth, G.; Levoska, J.; Uusimaki, A.; Vahakangas, J.; Leppavuori, S.; George, T.F. Thermal oxidation of porous silicon: Study on structure. Appl. Phys. Lett. 2005, 86, 041501. [CrossRef] 